\title{
Modern British Cemented Total Hip Replacement
}

\author{
Paul YF Lee ${ }^{*}$ and James Brock
}

Welshbone, South Wales Orthopaedics Research Network, Wales, UK

"Corresponding author: Paul YF Lee, Welshbone, South Wales Orthopaedics Research Network, Wales, UK, Tel: +447764614688; E-mail: paul@welshbone.com

Received date: October 12, 2016; Accepted date: October 14, 2016; Published date: October 20, 2016

Copyright: (c) 2016 Lee PYF, et al. This is an open-access article distributed under the terms of the Creative Commons Attribution License, which permits unrestricted use, distribution, and reproduction in any medium, provided the original author and source are credited.

Keywords: Cement; Total hip replacement; British; Charnley; Exeter; Wrightington

\section{Total Hip Replacement}

Total Hip Replacement (THR) is the most successful operation in medical history, and this editorial would like to take a look at the history of its development and how the contributions of great British orthopaedic surgeons made it possible. Britain continues to produce notable orthopaedic surgeons and special mention will go to the founding father of modern THR, Sir John Charnley. Further, the most popular stem in the world of 2015, the Exeter Stem V40, was developed in Britain with over 1 million being implanted in the last 46 years. The THR procedure gives people with disabling pain a chance to regain hold on their life, get out and walk freely again.

British orthopaedic surgeon, Sir John Charnley pioneered hip replacement with the development of a low friction arthroplasty (LFA) which saw publication in the Lancet in 1961 [1]. Previous replacement designs had been hampered by poor concept and material, ultimately leading to mechanical failure, however, this was to change as Charnley introduced 3 novel principles.

Firstly, the LFA concept which discerns that low friction between articular surfaces is dependent mostly upon the friction coefficients of the facing materials. This showed that the role of fluid was minimal, contrary to the leading theory at the time. This lead to the development of Teflon (PTFE) acetabular components and after initial setbacks with poor wearing and unsafe granulomatous mass formation, Charnley then learnt that high density Teflon (hdPTFE) could overcome these issues. This formed the second key principle; the use of hdPTFE as a bearing material. Results of first generation Charnley hip survivorship has been reported at $81 \%$ by Berry et al. with revision of any component as an end-point over a 25 year followup [2]. These findings are consistent with several other centres adding to the consensus that THR is the operation of the century, pioneered and made possible by British ingenuity [3,4].

Reasons for failure of first generation Charnley hip replacements included fracture of the implant [5] and aseptic loosening as a result of mechanical failure of the fixation interface [6], with increased rates also being widely reported in younger patients [7]. This swiftly led to improvements in patient selection and the development, of a third principle by Charnley, the use of acrylic cement to fix stem implant to bone. The use of polymethyl methacrylate has not largely changed, however the understanding that its successful use is highly technique dependent has. Cement was initially viewed as adhesive; however, modern understanding shows how important its role is in progressively changing the stiffness of the metal bone interface. Metal is 100 times stiffer than bone and simply using adhesive leads to the previously mentioned complications. The cement functions by mechanical interlock rather than adhesion, increasing surface area of attachment and thus strength. Improvements on the initial finger packing technique by Charnley include pressurization [8] and cleaning of the endosteal surface [9] to improve penetration of cement into bone interstices. These two studies highlight the subtle intricacies of the technology and its powerful impact on the success of total hip replacement.

Further improvements to stem incorporation, came through the Exeter Stem development over 40 years ago by Robin Ling and Clive Lee. Modern understanding of the stem shows that its polished design allows it to reside at the stem cement interface and the tapered shape, wider proximally, enables it to act as a self-locking wedge that preferentially transfers force to the femur, introduced ' the taper slip' principle. This design actually sees the stem continually tightening throughout the life of the hip. Long-term study has shown that this process continues and accumulates to a total of 1 to $2 \mathrm{~mm}$ of subsidence over 30 years [10]. This completely changed 'the composite beam' principle at the time, which was focusing on bonding the stem to the cement surface using textured and coated stems. Analysis of the Norwegian Arthroplasty Register pitted the best of British engineering against other popular prosthesis brands. The Charnley and Exeter systems were compared with Titan, Spectron and Link in an 18 year follow-up of 62,305 THRs [11]. In a ten year stem analysis the Exeter stem produced the best results, relative risk for aseptic loosening in half compared to the others [11]. It is also worth mentioning the work of another British surgeon from Wrightington, Wroblewski et al. who embraced the taper slip principle and identified a long term complication of proximal femoral strain shielding with the Charnley stem and designed the third taper. The triple taper design has been shown to improve loading of proximal and medial femur in the axial plane, this has been show to promote bone remodelling of the proximal femur due to beneficial loading medially [12].

Since its conception numerous changes have been made to the original Charnley design, British surgeons and engineers has embraced the taper slip principle and further develop the THR. Improvements to the hdPTFE have come through the development and rigorous testing of highly crosslinked, high density PTFE (hxPTFE). The AAOS 2014 John Charnley Award went to British student Geraint Thomas for his paper titled 'Long Term Wear of Highly Cross-Linked Polyethylene in Total Hip Arthroplasty'. In their high quality randomised controlled trial, they showed at 10 years averaged subsidence was $0.003 \mathrm{~mm} /$ year compared to $0.03 \mathrm{~mm} /$ year in the ultrahigh-molecular-weight PTFE group [13]. Further improvement has seen the recent rise of vitamin $\mathrm{E}$ treated hxPTFE with its superiority being demonstrated in short term, femoral head penetration trials [14].

Again changes in the acrylic cement have been subtle, with major improvement being the development of antibiotic impregnated cement. Systematic review and meta-analysis of over 6,000 arthroplasties reported the use of antibiotic impregnated cement can 
Page 2 of 2

half the rate of deep infection compared with controls [15]. Gentamicin impregnated cement was also shown to be the most superior [15].

The National Joint Registry UK (NJR UK) contains data from over 2 million joint replacement operations and continues to grow since its conception in 2002. In their 12th Annual Report in 2015, the NJR UK stated that uncemented THR remained the most common replacement, but its use had declined [16]. Hybrid fixation, for example cementation of the stem component and uncemented fixation of the acetabular component had increased. Kaplan-Meier cumulative risk was lowest $(3.63 \%)$ in the cemented group [16]. The cemented Exeter V40 now has a 10 year revision risk of 2.7\% [16]. The NJR UK suggested that cemented and hybrid hip replacement are increasing in popularity, the Exeter Hip continues to go from strength to strength. Cemented approaches are increasing in popularity due to their longevity and versatile use in patients. Cemented stems are less expensive and can also give the surgeon great flexibility to reproduce hip anatomy in the point of leg length, offset and neck shaft angle.

Perhaps most importantly THR, since its introduction, has proved to be consistently effective in reducing pain and to a lesser extent improving range of motion. The almost immediate pain relief and stark improvements in post-surgery disability related quality of life scores speak volumes. In a cohort study, looking at employment, nearly half of those unemployed before surgery were able to gain work after THR [17]. In younger individuals, THR enabled $89 \%$ of active preoperative individuals returned to sporting activity [18]. Obviously a decrease in high impact activity was observed, but no decrease in session length or frequency [18]. These two studies highlight the hugely positive impact a THR procedure may have on the daily life of an individual. Cost effective analysis of THR suggests that it is cost effective due to the high costs associated with custodial care and dependency [19]. THR may not perform as well in QALY analyses as life preserving procedures such as dialysis or coronary bypass, but its effect on disability and independence is unparalleled.

THR has been termed 'the operation of the century' and quite rightly so. Its effect on disability related quality of life is massive and continues to go from strength to strength. British engineers and surgeons have produced a reliable operation and developed a set of reliable cemented implants with a relatively low cost. This editorial has provided a summary of the groundbreaking contributions of British orthopaedic surgeons and engineers, hopefully, inspired readers to embrace the British tradition of innovation.

\section{References}

1. Charnley J (1961) Arthroplasty of the Hip: A New Operation. The Lancet 277: 1129-1132.

2. Berry DJ, Harmsen WS, Cabanela ME, Morrey BF (2002) Twenty-five-year survivorship of two thousand consecutive primary Charnley total hip replacements. J Bone Joint Surg Am 84: 171-177.
3. Callaghan JJ, Albright JC, Goetz DD, Olejniczak JP, Johnston RC (2000) Charnley total hip arthroplasty with cement. J Bone Joint Surg Am 82: 487-487.

4. Wroblewski BM, Fleming PA, Siney PD (1999) Charnley low-frictional torque arthroplasty of the hip. J Bone Joint Surg Br 81: 427-430.

5. Charnley J (1975) Fracture of Femoral Prostheses in Total Hip Replacement: A Clinical Study. Clin Orthop Relat Res 111: 105-120.

6. Charnley J (2012) Low friction arthroplasty of the hip: theory and practice. Springer Science \& Business Media, USA.

7. Chandler HP, Reineck FT, Wixson RL, McCarthy JC (1981) Total hip replacement in patients younger than thirty years old. A five-year follow-up study. J Bone Joint Surg Am 63: 1426-1434.

8. Askew MJ, Steege JW, Lewis JL, Ranieri JR, Wixson RL (1983) Effect of cement pressure and bone strength on polymethylmethacrylate fixation. J Orthop Res 1: 412-420.

9. Breusch SJ, Norman TL, Schneider U, Reitzel T, Blaha JD, et al. (2000) Lavage technique in total hip arthroplasty: jet lavage produces better cement penetration than syringe lavage in the proximal femur. J Arthroplasty 15: 921-927.

10. Ling RS, Charity J, Lee AJ, Whitehouse SL, Timperley AJ, et al. (2009) The long-term results of the original Exeter polished cemented femoral component: a follow-up report. J Arthroplasty 24: 511-517.

11. Espehaug B, Furnes O, Engesæter LB, Havelin LI (2009) 18 years of results with cemented primary hip prostheses in the Norwegian Arthroplasty Register: concerns about some newer implants. Acta Orthop 80: 402-412.

12. Wroblewski BM, Siney PD, Fleming PA (2001) Triple taper polished cemented stem in total hip arthroplasty: rationale for the design, surgical technique, and 7 years of clinical experience. J Arthroplasty 16: 37-41.

13. Glyn-Jones S, Thomas GE, Garfeld-Roberts P, Gundle R, Taylor A, et al. (2015) The John Charnley Award: Highly crosslinked polyethylene in total hip arthroplasty decreases long-term wear: a double-blind randomized trial. Clin Orthop Relat Res 473: 432-438.

14. Salemyr M, Muren O, Ahl T, Bodén H, Chammout G, et al. (2015) VitaminE diffused highly cross-linked polyethylene liner compared to standard liners in total hip arthroplasty. A randomized, controlled trial. Int Orthop 39: 1499-1505.

15. Wang J, Zhu C, Cheng T, Peng X, Zhang W, et al. (2013) A systematic review and meta-analysis of antibiotic-impregnated bone cement use in primary total hip or knee arthroplasty. PLoS One 8: e82745.

16. Powers-Freeling L (2015) NJR 12th Annual Report. National Joint Registry 12: 36.

17. Mobasheri R, Gidwani S, Rosson JW (2006) The effect of total hip replacement on the employment status of patients under the age of 60 years. Ann R Coll Surg Engl 88: 131-133.

18. Innmann MM, Weiss S, Andreas F, Merle C, Streit MR (2015) Sports and physical activity after cementless total hip arthroplasty with a minimum follow-up of 10 years. Scand J Med Sci Sports 26: 550-556.

19. Chang RW, Pellissier JM, Hazen GB (1996) A cost-effectiveness analysis of total hip arthroplasty for osteoarthritis of the hip. JAMA 275: 858-865. 